\title{
PERCEPÇÃO DOS ATORES SOCIAIS SOBRE OS BENEFÍCIOS SOCIOAMBIENTAIS COM A IMPLANTAÇÃO DO PARQUE NACIONAL DA CHAPADA DAS MESAS (MA)
}

Maria Lindalva Alves da Silva ${ }^{1}$

Maria de Fátima Veras Araújo ${ }^{2}$

Gonçalo Mendes da Conceição ${ }^{3}$

Resumo: O Parque Nacional da Chapada das Mesas foi implantado em terras particulares que abrangem os municípios de Carolina, Estreito e Riachão/MA. Foi criado por anseio popular em prol da conservação das cachoeiras do São Romão e da Prata, que seriam utilizadas na construção de duas hidrelétricas no curso do Rio Farinha. O objetivo da pesquisa foi investigar a percepção dos atores sociais do município de Carolina/MA, sobre a criação do Parque Nacional da Chapada das Mesas. A metodologia empregada foi a entrevista semiestruturada, com roteiro pré-estabelecido a 13 atores sociais. Os entrevistados compreenderam os ganhos socioambientais para os munícipes e visitantes, bem como a preservação dos ambientes naturais deste Parque.

Palavras-chave: Condições Socioambientais; Meio Ambiente; Unidade de Conservação.

1 Mestre em Biodiversidade, Ambiente e Saúde. Universidade Estadual do Maranhão (lindalva.maria@hotmmail.com)

2 Doutora em Geografia, Professora da Universidade Estadual doo Piauí (maria-veras@ig.com.br)

${ }^{3}$ Doutor em Zootecnia, Professor da Universidade Estadual do Maranhão( doutorgoncalo@gmail.com) 


\section{Introdução}

A realização de estudos sobre percepção ambiental possibilita averiguar circunstâncias peculiares relacionadas às tradições sociais, culturais e ambientais de um grupo de indivíduos que vivem em um determinado espaço territorial (HOEFFEL et al., 2008). Leff (2009), ressalta que esse grupo de pessoas conhecidas como comunidades locais são dotadas de conhecimentos que se desencadeiam em processos tecnológicos, ecológicos e culturais, portanto, necessitando de reconhecimento e valoração quanto ao fato de conviverem de forma cordial com a natureza.

O Parque Nacional da Chapada das Mesas (PNCM) foi criado em dezembro de 2005, na Mesorregião Sul maranhense em prol de uma demanda socioambiental, na qual a população temia a construção de duas hidrelétricas nas cachoeiras de São Romão e da Prata, situadas no curso do rio Farinha, um importante atributo natural para os moradores de Carolina e regiões adjacentes, que fazem parte dos estados do Maranhão e Tocantins.

No interior da Unidade de Conservação (UC) que, de acordo com a Lei Federal $n^{\circ}$ 9.985/000 (BRASIL, 2000), que classifica os parques nacionais, quanto à categoria é de Proteção Integral, com objetivo de contemplação, pesquisas científicas e atividades de Educação Ambiental (EA) e tem a presença de famílias que utilizam os recursos naturais para sua sobrevivência. Nessa perspectiva, justifica-se investigar a percepção de atores sociais do município de Carolina/MA, sobre a implantação do Parque em estudo.

\section{Caracterização da Área de Estudo}

O Parque Nacional da Chapada das Mesas está localizado sob as coordenadas $7^{\circ} 19^{\prime} 0^{\prime \prime} \mathrm{S}$ e $47^{\circ} 20^{\prime} 06^{\prime \prime} \mathrm{W}$, tem uma área de 160.046 .000 hectares de acordo com Instituto Chico Mendes da Conservação e Biodiversidade (ICMBio, 2016). A região onde foi implantada a UC, tem um grande potencial turístico por oferecer aos frequentadores, o contato com a natureza, contemplação e prática de turismo radical.

\section{Procedimentos da Coleta de Dados}

O estudo foi descritivo com abordagem qualitativa que na visão de Minayo (2010), a pesquisa científica, neste tipo de abordagem, permite comprovar a veracidade dos fatos e fenômenos estudados e promove a análise e a concepção de novos conceitos e valores a cerca do está sendo observado. Como procedimento metodológico, utilizou-se a entrevista semiestruturada de grupos focais, segundo a qual cada roteiro de entrevista foi elaborado conforme o segmento social de cada grupo, de acordo com estudos de Minayo (2010).

A pesquisa foi submetida à Comissão de Ética Pública, do Centro de Estudos Superiores de Caxias (CEP/CESC/UEMA), aprovada com número de protocolo 54126-1, e ao Sistema de Autorização e Informação do Instituto 
Chico Mendes de Conservação e Biodiversidade (SISBIO/ICMBIO), com o número de protocolo 576833165000055 para realização das entrevistas, além do Termo de Consentimento Livre Esclarecido que autorizava as gravações das entrevistas.

Os interlocutores desta pesquisa foram relacionados em 04 (quatro) quadros, com os seguintes dados específicos de cada grupo entrevistado: escolaridade/formação acadêmica, função/profissão, tempo de serviço/experiência profissional e as perguntas do roteiro da entrevista. Estes contribuíram voluntariamente com a perspectiva de colaborar com o estudo da percepção sobre a implantação e implementação da proposta do projeto da Unidade de Conservação e representam os segmentos sociais a seguir: professores de instituições públicas e privada, pessoas que representam o setor de turismo, representante do Sindicato de Trabalhadores Rurais, funcionários do ICMBio (analista ambiental e brigadistas contratados por meio de processo seletivo).

\section{Resultados e Discussão}

\section{Percepção dos Professores (as) sobre a criação do Parque Nacional da Chapada das Mesas}

Nesta primeira fase de entrevistas, foram ouvidos quatro sujeitos sobre as perguntas de acordo com sua formação e função, representados no Quadro 1 a seguir:

Quadro 1: Perguntas direcionadas aos professores do município de Carolina/MA.

\begin{tabular}{|c|c|c|c|}
\hline $\begin{array}{l}\text { Sujeitos da } \\
\text { pesquisa }\end{array}$ & Formação & Função & Perguntas \\
\hline $\begin{array}{l}\text { Escola } \\
\text { municipal }\end{array}$ & Licenciatura em Letras & $\begin{array}{l}\text { Coordenadora } \\
\text { Pedagógica }\end{array}$ & \multirow{4}{*}{$\begin{array}{l}\text { 1. Em qual categoria está } \\
\text { o Parque Nacional de } \\
\text { acordo com a lei } \\
9.985 / 2000 \text { ? } \\
\text { 2.Como foi sua } \\
\text { participação na Criação do } \\
\text { Parque Nacional? } \\
\text { 3. Realiza ou já realizou } \\
\text { atividade com alunos no } \\
\text { Parque Nacional? }\end{array}$} \\
\hline $\begin{array}{l}\text { Escola } \\
\text { estadual }\end{array}$ & $\begin{array}{l}\text { Licenciatura em } \\
\text { Geografia }\end{array}$ & $\begin{array}{l}\text { Professor do } \\
\text { ensino médio }\end{array}$ & \\
\hline UEMA & Licenciatura em Letras & $\begin{array}{l}\text { Coordenadora } \\
\text { do Polo da } \\
\text { UEMA }\end{array}$ & \\
\hline Escola privada & Licenciatura em Letras & $\begin{array}{l}\text { Professora } \\
\text { ensino } \\
\text { fundamental }\end{array}$ & \\
\hline
\end{tabular}

Fonte: Elaboração dos autores (2017).

A professora da rede municipal, ao se expressar sobre a categoria do Parque Nacional de acordo com a lei 9.985/2000, declara:

"Saber exatamente eu não sei, porque a gente trabalha nos dois termos, aqui é a Chapada, né, mas temos também a área de preservação da Amazônia Legal, a gente também faz parte dela. A categoria realmente eu não sel' (Professora Municipal). 
A referida professora, em seu depoimento, afirmou não saber claramente a que categoria pertence o Parque, segundo a Lei Federal $9.985 / 2000$. A docente deixa transparecer que a temática deveria ser mais discutida na escola, em virtude da sua criação ter ocorrido em área de Cerrado com prioridade máxima para a conservação da biodiversidade.

Essa declaração ancora-se na ideia de Tuan (1983), quando se refere que o contexto histórico-cultural depende do nível de interesse de cada indivíduo e vai despertar nele suas ideias e seus sentimentos ao longo de sua vida. Embora a entrevistada não saiba definir a categoria do Parque em estudo, ela está ciente da sua importância para preservação dessa área.

Ainda sobre essa questão, o professor da rede estadual, ressaltou:

"Não. De acordo com a lei, não. Não tenho conhecimento na área. Mas vejo que ele tem uma importância muito grande em relação aos parques da Chapada Diamantina e Chapada dos Veadeiros, parques de conservação com mais tempo no Brasil, mas ele tem grande importância, a relevância é a mesma" (Professor da Rede Estadual).

Infere-se que o entrevistado percebeu as vantagens socioambientais da criação do PNCM, ao compará-lo com outros parques implantados com o mesmo objetivo da UC em estudo. Sobre o que relatou o professor da rede estadual, Furlan (2000) considera o estudo sobre percepção ambiental o resultado da relação entre os aspectos naturais, sociais, culturais, econômicos e políticos. Dessa forma, a percepção do referido professor, está pautada nos benefícios ambientais, pelo fato de conservar a riqueza biológica do lugar e pela geração de renda impulsionada pelo turismo.

Os professores das redes municipal e estadual não comungam com o pensamento da professora da rede privada quanto à questão ao explicitar suas ideias:

"Não. Não sei. Mas sei da existência do Parque até porque abrange as terras dos meus pais. Não informaram quais seriam os impactos, quais seriam as necessidades a serem atendidas para quem tem terras no Parque" (Professora da Rede Privada).

$\mathrm{Na}$ concepção da professora da rede privada, percebeu-se que, embora as terras da sua família estejam nos limites onde foi implantada a UC, a mesma não se envolveu diretamente nas discussões sobre a proposta do projeto de implantação e os motivos da sua classificação na categoria segundo o Sistema Nacional de Unidades de Conservação. Conforme a fala desta entrevistada, torna-se relevante envolver todos os atores sociais na criação de áreas protegidas, pois isso corrobora com a sensibilização das pessoas, transformando-as em multiplicadoras e defensoras do projeto de implantação (BRESOLIN et al., 2010).

revista brasileira educação ambiental 
A ideia de sentimento de proteção foi externada na fala da professora da UEMA sobre a categoria do PNCM de acordo com a legislação em vigor:

"Não sei. Mas o Parque foi uma maneira que eles acharam de
proteger, guardar essa biodiversidade que tem em nosso
município" (Professora da UEMA).

A professora da UEMA não soube definir com clareza a classificação do Parque Nacional, porém, verificou-se a sua relação de amor e apego ao lugar ao inferir que a criação do Parque ajuda na proteção à biodiversidade da região.

De acordo com as falas dos interlocutores sobre a categoria do PNCM, constatou-se a preocupação com a preservação e conservação de ambientes físico-naturais de áreas protegidas para não só beneficiar o lugar onde se implantou a UC, mas também contribuir para a qualidade de vida das pessoas.

$\mathrm{Na}$ segunda abordagem, perguntou-se sobre a participação dos docentes na elaboração do projeto de criação do Parque Nacional. A professora da rede municipal afirmou:

"De certa parte sim, né, na Câmara Municipal, participei de alguns debates e seminários, mas não inteiramente" (Professora da rede municipal).

A referida docente deixa evidente que não se envolveu mais intensamente em movimentos de apelo social em benefício da criação do Parque, embora tenha participado esporadicamente de algumas mobilizações.

Já o professor da rede estadual, declarou:

"Eu compareci, mas só como ouvinte, em audiência pública foi solicitada algumas opiniões e relacionei alguns pontos na época" (Professor da rede estadual).

Embora o entrevistado tenha participado do processo como ouvinte, de alguma forma sua atuação foi mais efetiva, quando declarou que contribuiu com ideias no momento em que todos se reportavam ao projeto da implantação da UC. Nesse sentido, cabe mencionar Santos e Ramalho (2017), quando enfatizam que toda política pública deve nascer do anseio social em parceria com os órgãos governamentais, buscando compreender a situação socioeconômica da população envolvida.

Portanto, entendeu-se que o pesquisado acompanhou o processo, diferente da professora da escola privada: 
"Não. Para ser sincera, não me lembro de nenhum convite, apesar de ter voltado para a cidade há 14 anos, mas eu não vi, ouvi algumas movimentações a partir do momento em que tivemos interesse de nos desfazer de nossas terras que está dentro do Parque" (Professora da Rede Privada).

Pela fala da interlocutora, o processo de criação do PNCM envolve também a parte financeira das famílias que possuíam terras na área da nova UC, o que pode ter colaborado para o não envolvimento nas mobilizações sociais na época em que a sociedade lutava para implantação do Parque. Esse posicionamento colabora com as considerações de Martins (2012), ao enfatizar que os conflitos de terra constituem um dos problemas mais sérios das Unidades de Conservação no Brasil.

Quando se perguntou se os docentes realizam ou já realizaram atividade com alunos no Parque Nacional, a professora da rede municipal comentou:

"Não. Porque minha área é Língua Portuguesa. Eu trabalho na sala de aula, mais fora do Parque com produção textual, fazendo eles realizarem pesquisas para região de Carolina direcionado ao Parque Nacional' (Professor da rede municipal).

A docente compreende que as atividades relacionadas ao Parque em estudo devem ser trabalhadas na sala de aula, ou seja, os alunos precisam apenas de pesquisas bibliográficas para estudar o referido Parque. Essa concepção contraria o que pensam Santos e Silva (2017), ao ressaltarem a importância de atividades pedagógicas voltadas para educação ambiental que contribuam com a formação dos discentes. Os autores mencionaram 0 Programa Nacional de Educação Ambiental (ProNEA, 1999), como subsídio de ferramenta de ações educativas relacionadas às questões ambientais que podem ser trabalhadas de forma interdisciplinar. declara:

A professora da escola privada, sobre visitas ao Parque com os alunos,

"Não. Trabalho com Língua Portuguesa, não me especifiquei realmente nesta área. Vimos a nível mundial como Agenda 21, Greenpeace. Vimos coisas além da nossa realidade. Cadê a divulgação, o trabalho do município, será que seria só da professora preocupada com relatórios, acompanhamentos?" (Professora da Rede Privada).

A professora da UEMA ressaltou:

"Minha área é Língua Portuguesa. Eu fiquei afastada por quatro anos e foram nestes últimos quatro anos que aconteceram mais esses movimentos em cima da barragem" (Professora da UEMA).

Revbea, São Paulo, V. 13, № 2: 32-52, 2018.

revista brasileira educação ambiental 
Pelas revelações dos sujeitos supracitados entendeu-se que é preciso sensibilidade sobre a prática de aula de campo como atividade curricular de qualquer docente. Ao abordar a atividade extraclasse, o Ministério da Educação e Cultura lançou os Parâmetros Curriculares Nacionais (PCNs, 1997) com a proposta de nortear os docentes a trabalhar em sala de aula temas considerados interdisciplinares, entre eles, "meio ambiente".

Sobre as atividades pedagógicas e/ou visitas na área de preservação, o professor da rede estadual, comentou:

"Sim. Eu fiz ano passado com meus alunos. Questão de poluição dentro do Parque. Porque tem muito movimento de turistas dentro do Parque e falta fiscalização por parte desta questão do ICMBio. São 20 turistas para um guia. Às vezes, alguns deixam lixo, questão da poluição em geral' (Professor da Rede Estadual).

Sobre atividade extraclasse, esse interlocutor realiza ações no interior da UC, infere-se que uma atividade pedagógica em um ambiente natural deve ser uma estratégia usada pelo docente. Neste contexto, Sauvé (2005), afirma que atividade pedagógica como aulas de campo guiadas para ambientes naturais coloca o educando em contato com meio físico/natural e corrobora para que estes indivíduos compreendam a importância da EA na formação do docente.

\section{Percepção de representantes de outros segmentos sociais sobre os Impactos na criação do Parque Nacional}

Nesta segunda fase das entrevistas, foram ouvidos quatro sujeitos com formação e função diferentes, representadas no Quadro 2 a seguir:

Quadro 2: Perguntas do segmento do setor de turismo sobre a importância e ganhos ambientais com a implantação do PNCM

\begin{tabular}{|c|c|c|c|}
\hline $\begin{array}{l}\text { Sujeitos da } \\
\text { pesquisa }\end{array}$ & Formação & Função & Perguntas \\
\hline Comércio & Ensino médio & $\begin{array}{l}\text { Turista/ } \\
\text { Representante } \\
\text { comercial }\end{array}$ & \multirow{4}{*}{$\begin{array}{l}\text { 1. Qual a importância do Parque } \\
\text { para essa região do Maranhão? } \\
\text { 2.Quais as ações de infraestrutura } \\
\text { no município de Carolina } \\
\text { implantadas após a criação do } \\
\text { Parque Nacional? } \\
\text { 3.Quais foram os benefícios } \\
\text { ambientais aos munícipes com a } \\
\text { criação do Parque? }\end{array}$} \\
\hline $\begin{array}{l}\text { Agência de } \\
\text { turismo }\end{array}$ & $\begin{array}{l}\text { Especialista em Meio } \\
\text { Ambiente }\end{array}$ & Empresária & \\
\hline $\begin{array}{l}\text { Complexo } \\
\text { Pedra Caída }\end{array}$ & $\begin{array}{l}\text { Graduado em } \\
\text { Administração }\end{array}$ & Funcionário & \\
\hline $\begin{array}{l}\text { Sindicato dos } \\
\text { Trabalhadores } \\
\text { Rurais de } \\
\text { Carolina }\end{array}$ & Ensino Médio & Representante & \\
\hline
\end{tabular}

Fonte: Elaboração dos autores (2017). 
O Parque Nacional foi criado em uma região rica em mananciais hídricos, com cachoeiras e formações rochosas com forte atração para o turismo. Buscou-se, a seguir, investigar as percepções que estes sujeitos têm sobre a importância do Parque Nacional para essa região do Maranhão.

O primeiro entrevistado, o turista declarou que:

"Aqui por se tratar de uma região muito carente de recurso financeiro, é a maior riqueza hoje. Esta região atrai muitos turistas, que os meios de sobrevivência são poucos, a pecuária não é tão forte. Este Parque atrai muitos turistas, proporciona a economia funcionar muito bem, é de grande valor esse Parque nessa região" (Turista).

$\mathrm{Na}$ percepção do turista, o PNCM veio para corroborar com o desenvolvimento econômico nessa região que é carente de investimentos. De acordo como o Ministério do Turismo (2010), os parques têm gerado renda aos municípios com a frequência dos turistas.

Quando se reporta à importância do Parque Nacional, o representante do Complexo Turístico Pedra Caída expressa sua confiança nas políticas públicas de implantação de áreas protegidas para o desenvolvimento econômico de regiões como essa, onde foi implantado a UC:

"Imagino que o governo federal quando criou o Parque, criou políticas que trouxeram uma visualização maior, primeiro pela divulgação do Parque e depois a geração de empregos" (Representante Complexo Pedra Caída).

Com essa perspectiva, o Parque Nacional implantado em Carolina, com um cenário exuberante, tornou-se um atrativo de muitos turistas que querem desbravar sua paisagem natural. Nesse contexto, o funcionário do Complexo Turístico Pedra Caída, comentou:

"O Parque é importante demais. A criação do Parque tomou uma dimensão nacional e internacional' (Representante do Complexo Turístico Pedra Caída).

A criação de UCs se tornou um meio de fomentar o crescimento de países como o Brasil, dono de uma diversidade biológica, como confere sua paisagem de país tropical, que tem conseguido agregar ao turismo ecológico valores econômicos e chamar atenção de seus visitantes para as questões ambientais e a importância da conservação.

Ao se manifestar sobre a importância da UC na região Sul do Maranhão, a empresária da agência de turismo verbalizou: 
"Nossa! É imensa! Porque a gente vê o avanço da soja, da agropecuária, do eucalipto. Uma das maiores indústrias de papel e celulose do Brasil instalada aqui, a Suzano; se vê que o Cerrado está diminuindo" (Empresária da Agência de Turismo).

Percebeu-se que a empresária tem uma visão voltada para a qualidade de vida socioambiental, quando se refere à importância da criação desta UC. Destaca ainda, a preocupação com o desaparecimento do Cerrado, substituído por monoculturas. Estas questões vão de encontro às ideias de Viana e Rocha (2009), quando destacam que a conservação da biodiversidade pode promover a economia de uma região por meio da prática do turismo ecológico e formas sustentáveis de uso e ocupação do território.

A percepção da empresária sobre a importância do Parque Nacional para esta região do Maranhão comunga com a da representante do Sindicato dos Trabalhadores Rurais de Carolina:

"Para os Carolinenses foi como ganhar na mega sena, no começo a gente não entendia o que seria o Parque, não sabia que era uma coisa boa para a gente e para o município, mas com o tempo acharam" (Representante do Sindicato dos Trabalhadores Rurais de Carolina).

Esse depoimento evidencia a satisfação com a implantação da UC nessa região, supõe-se que a mobilização social foi reconhecida na fala da entrevistada na luta pela sua criação. Procurou-se verificar, através das falas dos sujeitos, ações de infraestrutura do município de Carolina que foram implantadas após a criação do Parque Nacional.

Sobre essa indagação, o turista comentou:

"Do município não. Eu creio que o setor privado tem contribuído muito pouco, né, para a geração de empregos” (Turista).

Para o turista, a atuação do município sobre as condições de infraestrutura não foram percebidas, porém, o setor privado tem investido de forma tímida. Diante desses argumentos pode se inferir que tanto o poder público, quanto o privado poderiam investir em ações estruturantes no município, beneficiando o setor do turismo, bem como todos os seus moradores. relata:

Sobre a referida questão, o funcionário do Complexo Pedra Caída,

"Na verdade, nos últimos pleitos, e esse agora que está aí, tem Revbea, São Paulo, V. 13, № 2: 32-52, 2018. 
dado apoio logístico, no caso tem mandado o secretário de Turismo pra feiras, para divulgar o Parque" (Funcionário do Complexo Pedra Caída).

Para o funcionário, a ação do município se restringe à divulgação do Parque, não se perceberam outras ações que são de obrigação do poder público na realização de obras, de acordo com suas expectativas. Considerase com essas proposições, que o executivo municipal colabore com o desenvolvimento do turismo da região, não apenas divulgar as belezas do Parque, mas com obras estruturantes,

Para a empresária da agência de turismo:

"As ações do município eu não consigo enxergar, não tem placas de sinalização na entrada do Parque, não sei se pode fazer isso, por conta de o Parque não ter plano de manejo, talvez não possa receber visitações, por conta de não ter o plano de manejo" (Empresária da Agência de Turismo).

A entrevistada não percebeu ações concretas após a criação da UC, quanto à adoção de medidas de melhoria dentre as citadas, outras como: vias de acesso adequado, saneamento básico, iluminação pública, necessários para o atendimento da atividade turística na região. A interlocutora mencionou também a ausência do plano de manejo da UC, que para Leuzinger (2010), representa as atividades e finalidades da criação de uma UC.

Outro aspecto citado pela empresária foi sobre as famílias que vivem no interior do Parque:

"As famílias que vivem lá têm muita pobreza, precisam de base técnica com investimento na agricultura familiar com produção orgânica livre de agrotóxico. Poderiam produzir frutas, hortaliças" (Empresaria da agência de turismo).

Essas famílias que vivem no interior da UC, pelo que foi abordado, deveriam ter mais assistência do município, principalmente, porque são pequenos agricultores que utilizam a terra para fazer seus plantios e criar seus animais, pois os munícipes têm direitos básicos, como o acesso à educação, saúde, moradia e ao apoio técnico para o uso do solo nas atividades agrícolas.

O entendimento da empresária da agência de turismo é o mesmo expresso por Costa (2002) e Costa (2013) ao concordarem que o nascimento de uma Unidade de Conservação pode proporcionar às famílias e aos órgãos executivos (ICMBio, Poder Público Municipal e Estadual) ganhos significativos, além de favorecer a qualidade de vida dos moradores e dos visitantes.

A representante do Sindicato dos Trabalhadores Rurais de Carolina destaca que o município tem oferecido ações de infraestrutura às famílias do 
Parque:

"Olha! Tem se sucedido muito bem. Em primeiro lugar por que a gente defende a presença das famílias dentro do Parque. A fonte de renda tem sido os turistas, porque eles não podem mais degradar a natureza. Tão vivendo de forma ecologicamente segura" (Representante do Sindicato dos Trabalhadores Rurais de Carolina).

Pelo que foi revelado, as famílias estão conseguindo sobreviver de maneira sustentável agregando renda através do turismo. Presume-se que essas famílias estão revendo seus conceitos sobre a forma do uso dos recursos naturais, pois antes sobreviviam do plantio de roças e criação de gado, e, atualmente estão utilizando alternativas de renda.

Ao se reportar sobre os benefícios ambientais aos munícipes com a criação do Parque, o turista comentou:

"Bom, como passo muito por aqui, sou representante comercial, eu costumo apreciar, desfrutar muito das belezas, as maravilhas deste Parque, muito rico em água. Sinto um bem-estar muito grande" (Turista).

Para o turista, o PNCM é um lugar onde as pessoas têm contato com a natureza, sentem bem-estar e contemplam sua beleza. Quanto aos benefícios do contato do ser humano com o ambiente físico/natural, Tuan (1983), relata em seu livro "Espaço e Lugar", que o ambiente pode marcar um indivíduo quando há uma conexão entre os mesmos.

Neste contexto, a visão de espaço para o entrevistado tem significados psicossociais, como o sentimento de afetividade que marcam a vida de todos os moradores da região, pela paisagem exuberante que dá uma sensação de bem-estar entre aqueles que visitam esses ambientes naturais conservados.

O funcionário do Complexo Turístico Pedra Caída, quando questionado sobre os benefícios ambientais, declarou que para os carolinenses foi a possibilidade de permanecer em sua cidade, tendo oportunidade de trabalho com a preservação do Parque:

"Mudanças excelentes, antes, quando os jovens terminavam o ensino médio precisavam ir embora fazer faculdade fora e ficava por lá mesmo. O Parque me deu a oportunidade de ficar na minha terra natal, ganhar um salário compatível e aos nativos também" (Funcionário do Complexo Turístico Pedra Caída). 
na vida, na opinião da empresária da agência de turismo e da representante do Sindicato dos Trabalhadores, com a criação da Unidade de Conservação em Carolina. Pelos laços afetivos, eles entendem que além da geração de emprego, através do turismo, a UC oportuniza outras vantagens, como a qualidade de vida socioambiental dos moradores de Carolina.

"Acho que ter um Parque ajuda na qualidade de vida, porque se você tem um ecossistema preservado numa região, impacta na qualidade de vida da gente" (Empresária da Agência de Turismo).

\section{Percepção dos Brigadistas sobre as atividades de combate aos focos de incêndios florestais no Parque Nacional}

Nesta terceira fase das entrevistas, foram ouvidos três sujeitos sobre as perguntas de acordo com sua formação e tempo de serviço, representados no Quadro 3 a seguir:

Quadro 3: Perguntas dirigidas aos representantes dos profissionais da brigada de incêndio.

\begin{tabular}{|l|l|l|l|}
\hline $\begin{array}{l}\text { Sujeitos da } \\
\text { pesquisa }\end{array}$ & Formação & Tempo de experiência & Perguntas \\
\hline Brigadista I & $\begin{array}{l}\text { Ensino fundamental } \\
\text { incompleto }\end{array}$ & $\begin{array}{l}\text { Tem } 5 \text { anos de } \\
\text { experiência }\end{array}$ & $\begin{array}{l}\text { 1. Quais são as dificuldades } \\
\text { no combate aos focos de } \\
\text { incêndio? } \\
\text { 2.Qual é a Infraestrutura do } \\
\text { ICMBIO para as ações de } \\
\text { Combate aos Incêndios? }\end{array}$ \\
\hline Brigadista II & $\begin{array}{l}\text { Ensino fundamental } \\
\text { incompleto }\end{array}$ & $\begin{array}{l}\text { Pouco tempo na } \\
\text { equipe }\end{array}$ & $\begin{array}{l}\text { 3.Relação entre os } \\
\text { brigadistas e a comunidade } \\
\text { no desenvolvimento das } \\
\text { Ações de Combate aos } \\
\text { Incêndios }\end{array}$ \\
\hline Brigadista III & $\begin{array}{l}\text { Ensino fundamental } \\
\text { incompleto }\end{array}$ & $\begin{array}{l}\text { Chefe da brigada e } \\
\text { mais antigo na } \\
\text { profissão }\end{array}$ & \\
\hline
\end{tabular}

Fonte: Elaboração dos autores (2017).

Em relação aos incêndios florestais quanto às dificuldades enfrentadas no combate ao fogo no Parque Nacional, o brigadista I declarou:

"No momento são as estradas. Muitas vezes você sai para o combate, mas as dificuldades para chegar aos incêndios são as estradas que não tem acesso" (Brigadista I).

O entrevistado analisa apenas as dificuldades de infraestrutura por parte do poder público, não considera dentre outras, a questão da profissionalização no trabalho cooperativo com os moradores em relação às técnicas básicas e complementares ao uso adequado ao combate dos incêndios.

O brigadista II destacou:

Revbea, São Paulo, V. 13, № 2: 32-52, 2018.

revista brasileira educação ambiental 
"Não achei muita dificuldade não, em combater os incêndios" (Brigadista II).

A visão do segundo entrevistado pode ser pelo fato do mesmo não ter participado das primeiras brigadas no início da implantação da UC, pois era a segunda vez que estava fazendo parte da equipe de brigadista.

Na visão do brigadista III:

"A dificuldade é o acesso. Muitos lugares não têm acesso. Os equipamentos antes não tinham, este ano tão chegando, acredito que vai ser melhor. Nos outros anos foi muito difícil, a estrutura não tinha transporte" (Brigadista III).

O pensamento dos interlocutores, sobre as dificuldades de combate aos incêndios se reporta às más condições das estradas, insuficiência de veículos e rádio de comunicação, de infraestrutura, tanto na parte de recursos humanos, quanto na aquisição de ferramentas, máquinas e equipamentos.

$\mathrm{Na}$ região da Chapada das Mesas, os moradores utilizam o fogo no manejo para o preparo das roças, conhecidas na região como "roças de toco" e preparo de pastagem para o gado. Nos meses de estiagem (setembro a dezembro), são registrados muitos focos de incêndio causados pela prática dessa atividade. Com a implantação da UC, houve a necessidade da criação brigada de incêndio para sensibilizar os moradores quanto ao uso do aceiro para minimizar ou controlar os incêndios florestais.

Sobre a infraestrutura do ICMBio, no que se refere ao apoio da equipe para as ações de combate aos incêndios, o brigadista I destacou:

"Dificuldades na comunicação. Hoje se eu chegar a quebrar lá dentro do Parque, não se comunica com a sede, a comunicação do rádio" (Brigadista I).

O brigadista II, ao comentar sobre a infraestrutura do órgão gestor, se reportou ao uso de equipamentos de proteção individual e ferramentas de combate aos incêndios:

"Acho que é o básico. Nós temos óculos, balaclava, luva, sandola, abafador, bomba costal e botas" (Brigadista II). terrestres:

O brigadista III, além dos EPIs, relacionou outros equipamentos

"Se tivesse mais equipamento era melhor. Bomba posta, abafador e outras ferramentas agrícolas, mas se tivesse outro Revbea, São Paulo, V. 13, № 2: 32-52, 2018. 
como trator. No caso de grande incêndio, precisa fazer acero manual não é concluído com eficiência e rapidez igual ao trator" (Brigadista III).

De acordo com as declarações dos entrevistados, a infraestrutura do PNCM está relacionada à ineficiência do número de veículos, às ferramentas de trabalho consideradas básicas e à comunicação que interfere no andamento das atividades. Ressaltam ainda, que as dificuldades enfrentadas pela gestão são reflexos da redução do aporte de recursos financeiros destinados ao bom andamento da gestão da UC em estudo, o que pode resultar na eficiência das atividades dos profissionais no combate ao incêndio.

Esse posicionamento dos brigadistas vai corroborar os estudos de Silva et al. (2003), ao se referir às atividades dos brigadistas quando ressaltam que um treinamento adequado aliado à qualidade de ferramentas, equipamentos máquinas, oportuniza confiança ao desempenho dos profissionais envolvidos.

Sobre a relação dos brigadistas e a comunidade no desenvolvimento das ações de combate aos incêndios, o brigadista I, comenta:

"Uma relação boa. Já teve ruim no começo, quando se criou o Parque. Mas, de certo tempo para cá, o povo está mais educado, o morador só queria queimar. Antigamente, era contra o ICMBIO, contra o Parque, mas com o trabalho do chefe do parque, em parceria com o morador, hoje eu posso dizer que $70 \%$ dos moradores estão mais educados" (Brigadista I).

O brigadista II se expressa quanto ao relacionamento das famílias com a sua equipe:

"O morador hoje ajuda bastante. Já entra em contato com a sede do ICMBio. Muitas vezes, ajuda a combater o fogo. A relação é muito boa com os moradores" (Brigadista II).

Na ótica do brigadista III:

"É muito importante, a gente ter o controle, parceria com o pessoal, se não, ficaria mais difícil, eles ajudam, dando apoio, contribuem com equipamento. Tem umas pessoas contra, que não é maioria" (Brigadista III).

Analisando as falas dos interlocutores, a realização das atividades de combate aos focos de incêndios, como a implantação do programa MIF e o envolvimento das famílias colaboram para o controle desses focos, no que se refere ao cumprimento das normas na forma adequada de fazer os aceiros para a preparação de suas roças.

revista brasileira educação ambiental 
A parceria entre a brigada e as comunidades remete à compreensão da relação dos moradores com o lugar onde vivem uma ferramenta usada pela gestão para sensibilizá-los quanto às questões de natureza ambiental, provocadas pela prática inadequada do uso do fogo.

\section{Percepção do Analista ambiental do ICMBIO sobre a implantação do Parque Nacional}

Nesta quarta fase de entrevista, foi ouvido um sujeito que é servidor do PNCM de acordo com sua formação e função, representado no Quadro 4 a seguir:

Quadro 4: Entrevista com o Analista ambiental do ICMBio do PNCM.

\begin{tabular}{|c|c|c|c|}
\hline $\begin{array}{l}\text { Sujeito da } \\
\text { pesquisa }\end{array}$ & Formação & Função & Perguntas \\
\hline $\begin{array}{l}\text { Funcionário } \\
\text { do PNCM }\end{array}$ & Nível superior & $\begin{array}{l}\text { Analista } \\
\text { ambiental }\end{array}$ & $\begin{array}{l}\text { 1. Quais foram os } \\
\text { desafios/dificuldades } \\
\text { na implementação do } \\
\text { Parque Nacional? } \\
\text { Qual a relação entre } \\
\text { a Educação Ambiental } \\
\text { e o fogo como questão } \\
\text { cultural e causador de } \\
\text { impactos negativos? } \\
\text { 3. Fale sobre a } \\
\text { regularização } \\
\text { fundiária/Plano de } \\
\text { Manejo e Parcerias }\end{array}$ \\
\hline
\end{tabular}

Fonte: Elaboração dos autores (2017).

O analista ambiental enfatizou que a gestão da Unidade de conservação está dividida em duas vertentes: "tem a gestão territorial e a gestão administrativa". Seu depoimento se embasa no $\S^{\circ}{ }^{\circ}$, art. $7^{\circ}$ do Sistema de Unidades de Conservação (BRASIL, 2000). destacou:

Sobre a questão dos desafios/dificuldades, o referido analista

"O Parque foi criado para conservação da biodiversidade, proteção das belezas cênicas e a possibilidade de serviços ambientais para a sociedade em geral' (Analista Ambiental).

Ainda sobre os desafios em frente à gestão, o pesquisado ressaltou:

"O Parque é muito recente, foi criado em uma época onde se moldava um modelo de gestão ambiental no país e se criavam outras estruturas de gestão" (Analista ambiental). 
Pelo seu depoimento, entendeu-se que a criação da UC ocorreu em um momento de grandes mudanças na estrutura da gestão das Unidades de Conservação no Brasil, com a criação do Instituto Chico Mendes, o qual passou a ser responsável pela gestão dos Parques.

Sobre a questão em pauta, o entrevistado:

"O Parque foi criado em 2005 e só em 2007 foi lotado o primeiro servidor. Em 2007 houve a separação do IBAMA em dois órgãos e o Parque foi criado quando ainda era o IBAMA, chegou o primeiro servidor já tinha criado outro órgão, estava em encaminhamento a divisão dos dois órgãos" (Analista Ambiental).

De que acordo com depoimentos do analista, um dos seus desafios está relacionado ao número insuficiente de servidores e à complexidade em montar uma equipe para implementação de ações efetivas, que garantam cumprir as finalidades da criação da UC, de acordo com a Lei 9.985/2000 e as expectativas da sociedade.

O interlocutor relata que outros servidores não se sentem atraídos pela região devidos a distância dos centros urbanos. Outra dificuldade é a não oferta de novas vagas através de concurso público. Essa deficiência do número de funcionários faz parte da vivência de outras Unidades de Conservação no Brasil, que em conjunto com a participação dos moradores e a deficiência de recursos financeiros são os principais gargalos na efetivação das áreas protegidas, na concepção de Terborhl et al. (2000) e Gonçalves et al. (2011), realidade encontrada no PNCM.

Sobre a relação entre a Educação Ambiental e o fogo como questão cultural e causador de impactos negativos, o analista ambiental, destaca:

"Em ambiente de Cerrado é um problema ambiental complexo que faz parte da necessidade das comunidades, sempre vai ter algum impacto se não for mediado, vai gerar um conflito" (Analista Ambiental).

Subentendeu-se na fala do interlocutor que a cultura do fogo é uma técnica usada pelas comunidades rurais e há possibilidade de usá-la de forma controlada, causando menos impacto à vegetação. Destacou também que ao chegar para administrar o Parque, encontrou um conflito entre moradores e o IBAMA, gerado pela imposição da sua legislação, assim como a revolta dos moradores devido à questão cultural no seu sistema de produção:

"Você tem um Parque criado em cima de comunidades rurais desavisadas, não sabiam o que era a proposta e qual o papel deles e passaram a ser proibidos de praticar seus modos de vida, e a primeira delas é não ter pessoa morando dentro" (Analista Ambiental).

Revbea, São Paulo, V. 13, № 2: 32-52, 2018.

revista brasileira educação ambiental 
Sobre as experiências vivenciadas pelo analista no acompanhamento in loco das atividades no combate aos focos de incêndios florestais ocorridos em períodos de estiagem e provocados, às vezes, pelos moradores durante 0 preparo do terreno para uso atividade agrícola, inferiu-se que em sua atuação à frente da gestão foram realizadas atividades de EA voltadas para a sensibilização dos moradores no cuidado do preparo das roças e dos pastos, visando reduzir a quantidade de focos de incêndios na região do Parque.

Desta forma, a colaboração dos moradores foi essencial para as metas desejadas pelo programa MIF. Segundo o entrevistado:

"Foram divididas as responsabilidades com a política do monitoramento do fogo controlado, pois, se a comunidade não ganhar nada com a proteção, ela não vai proteger o meio ambiente" (Analista Ambiental).

Infere-se que a atuação do analista na época em que assumiu a gestão do Parque e sua relação como os moradores foram moldados através de estratégias de Educação Ambiental que geraram mudanças de comportamento quanto à preservação da fauna e da flora do local. analista:

A regularização fundiária/Plano de Manejo e Parcerias na visão do

"Hoje o ICMBio tem duas preocupações sobre as desapropriações: primeiro, o que vai ser deste território sem ninguém, do ponto de vista ambiental e ecológico. São ambientes moldados pela presença humana e você vai ter que tirar, não se sabe o que isto vai virar. Em segundo lugar, o que vão fazer com essas pessoas? O que elas vão fazer?' (Analista Ambiental).

O entrevistado mostrou sua preocupação com o destino dessas famílias: "são 130 famílias e em Carolina não existem terras em condições de assentamento para a reforma agrária, para a produção de agricultura familiar". Ainda relatou que em Carolina, não há terras com qualidade para programa de assentamento da agricultura familiar:

"todas as terras já foram vistoriadas pelo INCRA, todas foram recusadas pela falta de condições, que incluem a fertilidade do solo" (Analista ambiental).

As inferências do analista estão pautadas nas citações de Medeiros e Young (2011), quando ressaltaram que na política de criação de áreas protegidas, as questões fundiárias têm sido problema recorrente no processo de implantação das Unidades de Conservação. 
Quanto ao Plano de Manejo, o analista comentou:

"Não tem plano de manejo por falta de pessoal. Se tivesse uma equipe poderia ter uma estrutura física, um centro de visitantes, muito do seu território poderia já estar desapropriado, poderia ter um projeto de Educação Ambiental mais ambicioso" (Analista Ambiental).

Ao explicar os motivos do Parque ainda não ter construído seu Plano de Manejo, inferiu-se que essa realidade reflete a fragilidade da legislação do Sistema de Unidades de Conservação/Ministério do Meio Ambiente, que cria novas áreas protegidas, mas não dá apoio técnico e financeiro para a efetivação de áreas recém-criadas. Essas observações foram expostas por Medeiros e Young (2011), ao mencionarem a falta de plano de manejo para consolidar as ações que efetivam uma unidade de conservação.

$\mathrm{Na}$ ótica de Leuzinger (2010), o plano de manejo em uma área de conservação conduz toda a gestão de uma unidade, nele deve estar incluída a zona de amortecimento, corredores ecológicos e medidas mitigatórias para promover a integração da vida econômica e social das comunidades do entorno de uma UC.

No tocante à parceria, destacou:

"Infelizmente as parcerias não aconteceram ainda motivadas por movimentações políticas, na estrutura da gestão que não se consolidaram" (Analista Ambiental).

Ao se guiar pelo objetivo de compreender a visão do analista ambiental quanto à implementação do Parque Nacional e seus desafios na sua implementação, é possível entender a complexidade pressuposta na efetivação legalmente instituída. Ademais, a legislação tem suas próprias contradições, entre o que está posto institucionalmente e o que de fato acontece na trajetória de operacionalização, que ocorre em caminhos lentos e tortuosos.

\section{Considerações Finais}

As informações prestadas através da pesquisa sobre a percepção de atores sociais a respeito da criação do Parque Nacional da Chapada das Mesas permitiram avaliar o perfil de cada entrevistado no tocante a sua atuação socioambiental.

Os docentes que participaram da entrevista entendem que não são necessárias as atividades extraclasses com alunos no Parque. Na ótica da maioria, é preciso apenas falar da importância da UC como espaço de preservação e onde se pode desenvolver atividades de educação ambiental.

revista brasileira educação ambiental 
Quando foi criado o Programa Nacional de Educação Ambiental, este tem como objetivo primordial, a conscientização de cidadãos sobre a importância da conservação e preservação, no sentido de se garantir um ambiente mais equilibrado ecologicamente, sendo estendido para as instituições de ensino formais e não formais. Assim, estados e municípios, através das secretarias de educação, têm a responsabilidade de ofertar formação continuada aos professores desenvolvam ações da temática meio ambiente de forma interdisciplinar através de projetos pedagógicos e sua inserção no currículo escolar.

A UC oferece aos turistas e às famílias residentes ambiente de contemplação pela riqueza de suas belezas cênicas e o contato com a biodiversidade de fauna e flora, e ao mesmo tempo, oportuniza o desenvolvimento econômico da região através do turismo ecológico na visão dos que representam o setor de turismo de Carolina.

O estudo também demonstrou na categoria dos 'brigadistas', que os focos de incêndio provocados na época do preparo do solo para a prática da agricultura familiar dos seus residentes, estão ocorrendo de forma mais planejada com participação das famílias. Essas medidas vão de encontro à finalidade da criação da UC, que é a preservação e práticas sustentáveis.

Segundo o representante do Instituto Chico Mendes, a efetivação do Parque Nacional depende de ações imediatas como a construção do Plano de Manejo, a regularização fundiária das famílias residentes e servidores para que não seja uma Unidade de Conservação apenas no papel, mas que tenha de fato sua implementação. Portanto, urge adotar estratégias para as questões socioambientais e que o Estado dê legitimidade através de políticas públicas que deverão ser regulamentadas através de seus órgãos instituídos.

\section{Referências}

BRESOLINI, A.J.; ZAKEVSKI, S.B.B.; MARINHO, J.R. Percepção, comunicação e educação ambiental em Unidades de Conservação: um estudo no parque estadual de espigão Alto-Barracão/RS. Perspectiva, Erechim, v.34, n.128, p. 103-114,2010. Disponível em <http://www.uricer.edu.br/site/pdfs/perspectiva/128_141.pdf>. Acesso em: 05. Maio. 2018.

BUARQUE, S.C. Construindo o desenvolvimento Local Sustentável. $4^{\mathrm{a}}$ ed. Rio de Janeiro. Guaramond, 2008.

BRASIL. Lei no 9.985, de 18 de julho de 2000. Sistema de Unidades de Conservação. Disponível em <http://www.icmbio.gov.br/sisbio/images/stories linstrucoes normativas/SNUC.pdf> Acesso em: 05. Maio. 2018.

BRASIL.Parâmetros Curriculares Nacionais: Meio Ambiente. Ministério da Educação. Secretaria do Ensino Fundamental. Brasília, 1997. Disponível em $<$ http://portal.mec.gov.br/seb/arquivos/pdf/livro01.pdf>. Acesso em: 10. Abril. 2018. 
BRASIL.Programa Nacional de Educação Ambiental. 2. ed. Brasília: MMA, 2014. Disponível $<$ http://www.mma.gov.br/estruturas/educamb/ arquivos/pronea3.pdf $>$. Acesso em: 04. Maio. 2018.

COSTA, $H$. Destinos do turismo: percursos para a sustentabilidade. $1^{1}$ ed. Rio de Janeiro: FGV, 2013.

COSTA, P.C. Ecoturismo. Coleção ABC do turismo. São Paulo: Aleph, 2002.

FURLAN, S. A. Lugar e cidadania: implicações socioambientais das políticas de conservação ambiental. Situação do Parque Estadual da Ilhabela na ilha de São Sebastião. 2000. Tese. (Doutorado em Geografia). Programa de PósGraduação em Geografia Física. Faculdade de Filosofia, Letras e Ciências Humanas. USP, São Paulo.

GONÇALVES, M.P. BRANQUINHO, F.T.B.; FELZENSZWALB I. Uma análise contextual do funcionamento efetivo e participação popular em uma unidade de conservação: o caso da área de proteção ambiental de Petrópolis (Rio de Janeiro: Brasil). Sociedade \& Natureza, v.23, n.2, 2011, p.323-334.

HOEFFEL, J. L.; FADINI, A. B. A.; MACHADO, M.K.; REIS, J.C. Trajetórias do Jaguary - Unidades de Conservação, Percepção Ambiental e Turismo: um estudo na APA do Sistema Cantareira, São Paulo. Ambiente e Sociedade. Campinas, v. 11, n. 1, p. 131-148, 2008.

IMBIO. Nota Técnica no 001/2016. Disponível em $<$ http://d1ij67glom3ric.cloudfront.net/.../Relatorio\%2BM\%25C3\%258EF\%2B

Parque\% >. Acesso em: 14. Abril. 2017.

LEUZINGER, M. D. Uso público em Unidades de Conservação. Anais do Congresso de Direito Ambiental da PUC-RIO. Rio de Janeiro-RJ, 2010. Disponível em: $<$ http://www.nima.pucrio.br/aprodab/artigos/uso publico em unidades de con servacao marcia leuzinger.pdf>. Acesso em: 20. Abril. 2017.

LEFF, E. Ecologia, Capital e Cultura: a territorialização da racionalidade ambiental. Editora Vozes: Petrópolis - RJ, 2009.

MINISTÉRIO DO TURISMO. Ecoturismo: Orientações básicas, 2. ed. BrasíliaDF: $2010 . \quad$ Disponível em: $<$ http://www.turismo.gov.br/export/sites/default/turismo/o ministerio/publicacoes /downloads publicações/Ecoturismo Versxo Final impresso .pdf> Acesso em: 15. Abril. 2017.

MINAYO, M.C.S. (org.). Pesquisa social: teoria, método e criatividade. $29^{a}$ ed. Petrópolis, RJ: Vozes, 2010.

MARTINS, A. Conflitos ambientais em Unidades de Conservação: dilemas da gestão territorial no Brasil. Revista Bibliográfica de Geografía y Ciencias Sociales. V. XVII, n. 989, 2012.

MEDEIROS, R.; YOUNG, C.E.F. Contribuição das Unidades de 
Conservação brasileiras para a economia nacional: Relatório Final. Brasília: UNEP-WCMC, 2011. $\quad 120 \quad$ p. $\quad$ Disponível em $<$ http://www.icmbio.gov.br/portal/images/stories/comunicacao/estudocontribuica o.pdf>. Acesso em: 05. Maio. 2018.

SANTOS, P.J.A.; RAMALHO, A.M.C. Impactos socioambientais do Programa Caminhos da Paraíba no Município de Coxixola, nordeste brasileiro. Revista Espacios. v. 38, n.12, 22p. 2017.

SAUVÉ, L. Uma cartografia das correntes em educação ambiental. In: Sato, M.; Carvalho, I. C. M. (Org). Educação Ambiental Pesquisa e Desafios. Porto Alegre: Editora Artmed, 2005, p.17-45.

SILVA, V.M.; SILVA, B.T.B. Percepção ambiental da comunidade do entorno do Parque natural municipal Barão de Mauá, município de Magé, RJ. In: Anais... Uso Público em Unidades de Conservação, n. 1, v. 1. p. 200-210, 2013. Disponível $<$ www.sbecotur.org.br/revbea/index.php/revbea/article/download/5093/3396. Acesso em: 05/ maio. 2018.

SILVA, J.C.; FIEDLER, N.C.; RIBEIRO, G.A.; SILVA JUNIOR, M.C. Avaliação de brigadas de incêndios florestais e unidade de conservação. Revista Árvore, Viçosa, MG, v.27, n.1, p.95-101, 2003.

SANTOS, F.R.; SILVA, A.M.S. A importância da educação ambiental para graduandos da Universidade Estadual de Goiás: Campus Morrinhos. INTERAÇÕES, Campo Grande, MS, v. 18, n. 2, p. 71-85, 2017.

TUAN, Y. Espaço e Lugar: a perspectiva da experiência. São Paulo: DIFEL, 1983.

TERBORGH; J.; SCHAIK, C.V. DAVENPORT, L.; RAO, M. Tornando os Parques eficientes: estratégias para a conservação da natureza nos trópicos. Curitiba: UFPR/Fundação Boticário; 2002. 518 p.

VILHENA, R.H.; OLIVEIRA, M.P. Percepção ambiental e qualidade de vida sob o olhar do cidadão: estudo de caso na vila de São Francisco de ArapixiChaves-llha do Marajó-PA. Anais do $\mathrm{V}$ Encontro Nacional da ANPPAS. Florianópolis-SC, 2010.2 Disponível em $<$ http:// www.anppas.org.br/encontro5/cd/artigos/GT3-486-436-20100831125639.pdf>. Acesso em: 05. Maio. 2018. 